\title{
BMJ Global Health Reinforcing locally led solutions for universal health coverage: a logic model with applications in Benin, Namibia and Uganda
}

\author{
Joël Arthur Kiendrébéogo (D) , ${ }^{1}$ Andrea Thoumi, ${ }^{2}$ Keith Mangam, ${ }^{3}$ Cheickna Touré, ${ }^{3}$ \\ Seyni Mbaye, ${ }^{3}$ Patricia Odero, ${ }^{4}$ Edward Owino, ${ }^{3}$ Claire Jones, ${ }^{5}$ \\ Grace Ssali Kiwanuka, ${ }^{6}$ Zilper Audi, ${ }^{4,7}$ Danielle Bloom, ${ }^{3}$ Amelia Kinter, ${ }^{3}$ \\ Allison Gamble Kelley ${ }^{3}$
}

To cite: Kiendrébéogo JA Thoumi A, Mangam K, et al. Reinforcing locally led solutions for universal health coverage: a logic model with applications in Benin, Namibia and Uganda. BMJ Global Health 2021;6:e004273. doi:10.1136/ bmjgh-2020-004273

Handling editor Seye Abimbola

Received 21 October 2020 Revised 28 January 2021 Accepted 30 January 2021
Check for updates

(c) Author(s) (or their employer(s)) 2021. Re-use permitted under CC BY-NC. No commercial re-use. See rights and permissions. Published by BMJ.

For numbered affiliations see end of article.

Correspondence to Dr Joël Arthur Kiendrébéogo; jkiendre@gmail.com

\section{ABSTRACT}

Development assistance for health programmes is often characterised as donor-led models with minimal country ownership and limited sustainability. This article presents new ways for low-income and middle-income countries to gain more control of their development assistance programming as they move towards universal health coverage (UHC). We base our findings on the experience of the African Collaborative for Health Financing Solutions (ACS), an innovative US Agency for International Development-funded project. The ACS project stems from the premise that the global health community can more effectively support UHC processes in countries if development partners change three long-standing paradigms: (1) time-limited projects to enhancing longlasting processes, (2) fly-in/fly-out development support to leveraging and strengthening local and regional expertise and (3) static knowledge creation to supporting practical and co-developed resources that enhance learning and capture implementation experience. We assume that development partners can facilitate progress towards UHC if interventions follow five action steps, including (1) align to country demand, (2) provide evidence-based and tailored health financing technical support, (3) respond to knowledge and learnings throughout activity design and implementation, (4) foster multi-stakeholder collaboration and ownership and (5) strengthen accountability mechanisms. Since 2017, the ACS project has applied these five action steps in its implementing countries, including Benin, Namibia and Uganda. This article shares with the global health community preliminary achievements of implementing a unique, challenging but promising experience.

\section{INTRODUCTION}

Many governments in low-income and middle-income countries are responding to demand to increase their populations' access to healthcare and providing financial protection against impoverishment due to
Summary box

Technical assistance to low-income and middleincome countries in the health sector often takes a top-down approach, coming as a prepackaged set of activities that stifles programme co-design and local capacity building in a way that skirts real country needs and hampers local ownership.

- Innovative approaches are needed to equip local communities and governments with the required skills and resources to put countries in control so that local actors can steer their own universal health coverage (UHC) processes and maintain responsibility to move them forward.

- Experience from three countries in sub-Saharan Africa suggests processes focused on promoting demand-driven knowledge exchanges and learning, multi-stakeholder and sectoral collaboration, and accountability mechanisms hold great potential to help overcome obstacles in progressing towards UHC.

- Supporting change is a long-term endeavour, and broad support from all stakeholders is essential for a real paradigm shift in donors' relations with their country counterparts, for effective and lasting results.

the financial burden of illness. ${ }^{12}$ Yet, countries continue to experience major obstacles in designing and implementing efficient and equitable health financing policies and programmes. ${ }^{34}$ These obstacles are diverse and technical, but also related to countryspecific sociocultural, economic or political dynamics. ${ }^{5}$ Prior work notes the critical role of learning, ${ }^{67}$ local ownership, ${ }^{8}$ collaboration and multisectoriality, ${ }^{9}$ community participation, ${ }^{10}{ }^{11}$ private sector involvement ${ }^{12} 13$ and accountability mechanisms ${ }^{14}$ in achieving better health results—and universal health 
coverage (UHC) as a result. But there is a gap in implementing these elements in practice, and the role that external partners can play is not always clear. In addition, the way donor aid is organised and structured, including the predominance of top-down, time-limited and insufficiently coordinated approaches among interventions, creates a misalignment with countries' procedures and mechanisms. ${ }^{1516}$

To face these challenges, Kelley and Cashin ${ }^{17}$ suggest three paradigm shifts that recentre power back into the hands of countries to shape and scope UHC-related activities that are aligned to their health priorities. These shifts include moving (1) from supporting timelimited projects to enhancing long-lasting processes, (2) from fly-in/fly-out development support to leveraging and strengthening local and regional expertise and (3) from static knowledge creation to supporting practical and co-developed resources that enhance learning and capture implementation experience. This article proposes a logic model for development partners to embody these three shifts and effectively listen, learn and structure support to countries in sub-Saharan Africa to advance their UHC goals. This logic model is drawn from the experience of implementing the African Collaborative for Health Financing Solutions (ACS), a 5-year (2017-2022) US Agency for International Development (USAID)-funded project. First, we describe how these paradigm shifts informed the design and development of ACS, including the project's theoretical foundations. Then, we present the initial conceptual framework of the project that informed the logic model. Based on emerging best practices from a few countries where ACS provides support, we explain and illustrate core elements of this logic model that can be applied to broader global health contexts beyond ACS.

\section{THE NEED TO RECENTRE DEVELOPMENT ASSISTANCE TO COUNTRY OWNERSHIP}

The primary vision of ACS is to support countries to build local capacity, instil mutual trust and local ownership, and adopt, adapt and implement strategies towards UHC that are likely to work in their unique contexts and that go beyond the project's lifespan. In line with the three paradigm shifts mentioned above, the ACS project has focused on enabling locally led solutions that are responsive to country needs through country engagements using consultative approaches to understand local needs and perspectives. The project also draws local institutions into strategy and implementation of its activities as lead partners.

From the inception of the project, ACS assumed that while there may be access to technical know-how around policies and best practices, countries' progress towards UHC is conditioned by a focused approach to (1) sharing knowledge and learning throughout activity design and implementation, (2) fostering multi-stakeholder collaboration and ownership and (3) strengthening accountability mechanisms. Successful models of collective engagements, especially the 'Collective Impact' model proposed by Kania and Kramer, inspired the ACS approach. ${ }^{18}$ The 'Collective Impact' model is structured around the following five constructs: a common agenda, shared measurement systems, mutually reinforcing activities, continuous communication and backbone support organisations. To put these constructs into action, the ACS project team set out to support country and regional stakeholders by acting as the backbone support organisation while collaborating with country partners to create a work plan that is demand-driven and structured. In addition, the project saw the need to co-develop shared measurement and activities that are designed to not just guide project work but act as a shared agenda — this step could support accountability and guide multisectoral action in country. Finally, ACS noticed that ongoing communication on countries' technical and capacitation needs is key to support learning.

Using three core areas-learning, collaboration and accountability-the ACS team developed an initial conceptual framework that built on other previous frameworks such as the WHO building blocks ${ }^{19}$ and the health systems strengthening cube. ${ }^{20}$ The ACS conceptual framework (figure 1) integrated many influencing factors, including the enabling environment (eg, socioeconomic factors, global and national commitments, technical and technological progress, organisational culture, public financial management system, political will, institutional arrangements, policies and processes), stakeholder dynamics (inclusion, multisectoral and multi-stakeholder participation), the state of local health financing functions (revenue mobilisation, pooling and purchasing) $)^{21}$ and other health system building blocks (service delivery, human resources, medical products and technologies, information, research and stewardship). ${ }^{19}$ The framework also considers the role and influence of country and regional stakeholders-including, but not limited to, the Ministries of Health (MOHs), other government agencies, civil society and private sectorwho are critical players in supporting movement towards the achievement of UHC goals.

This framework played a critical role in helping to ground thinking during the early stages of the project, specifically during and after consultation phases conducted between September and December 2017 in Burkina Faso, Nigeria, Senegal, Tanzania and Uganda. These consultations, carried out with about 200 people including health leaders across public, private and community sectors and levels of implementation, as well as global and regional stakeholders, validated the hypothesis of ACS regarding the relevance and crucial role of learning, collaboration and accountability to advance UHC processes. Key findings from these consultations are summarised in box $1 .^{22}$

\section{ACS LOGIC MODEL TO IMPLEMENT THEORY TO ACTION}

Following findings from the consultation phase, and after multiple rounds of validation and refinement, the 
VISION

Countries in SSA supported to promote health financing policies and processes that advance UHC

ACS AREAS

OF FOCUS

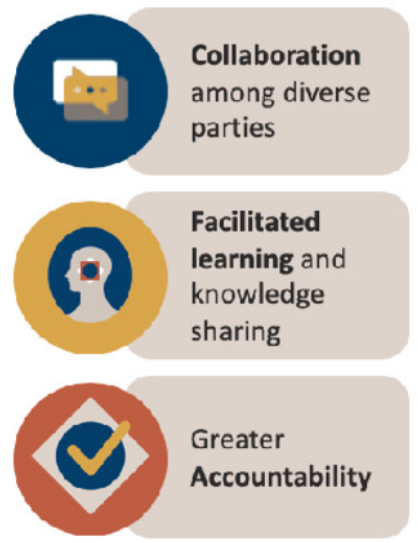

Enabling

Environment
COUNTRY

OUTCOMES
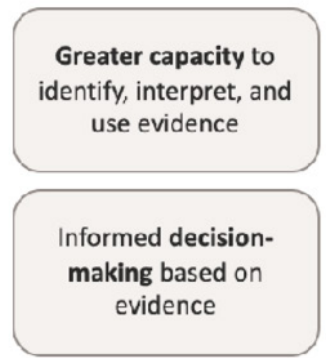

Accelerated

Implementation of

$\mathrm{UHC}$ policies and programs
UHC GOALS

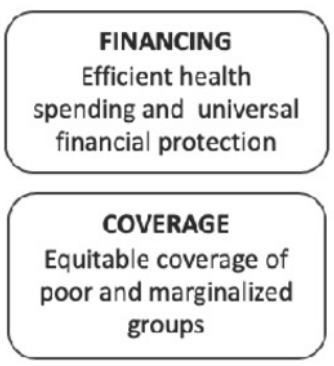

SERVICES

Access to a package of quality services

Figure 1 Conceptual framework highlighting the original three key functions of ACS. ACS, African Collaborative for Health Financing Solutions; SSA, sub-Saharan Africa; UHC, universal heath coverage.

conceptual framework helped define what the key pillars of the project, including learning, collaboration and accountability, should entail. The framework was critical in helping to design the ACS packages of support in implementation countries but did not specify activities and expected outputs clearly enough for project measurement purpose. As a result, the team developed a more linear logic model (see figure 2), which expanded the three key focus areas into five core functions. The logic model attempts to demonstrate how these core functions, which represent the five main types of support

Box 1 Key barriers to UHC processes identified in countries from ACS initial consultation phase

- Barriers to accountability despite the existence of accountability frameworks: limited ability to translate policy to implementation and lack of clear implementation strategies.

- Barriers to collaboration: lack of effective engagement, poor stakeholder inclusion, fragmentation of efforts and poor coordination of UHC platforms.

- Barriers to implementation: insufficient financial resources, inefficient allocation of existing resources, lack of a standard process for information sharing, insufficient use of evidence to guide decisionmaking, and organisational or cultural barriers to knowledge exchange for learning.

- Barriers to accessibility (especially for the poor and people living in rural settings): insufficient human resources, supplies and commodities, as well as inadequate infrastructure and service delivery systems.

ACS, African Collaborative for Health Financing Solutions; UHC, universal heath coverage.
ACS brings, can work together in a mutually reinforcing way to achieve the project's outputs and outcomes. The flow of the logic model concludes by linking these ACS outcomes to two higher level, long-term impact statements that ultimately contribute to the overall goal of more efficient and equitable progress towards UHC. This goal exists beyond the confines of the ACS project's influence, resources and timeline, but demonstrates where ACS hopes to contribute to over the course of 5 years.

The logic model assumes that these five core functions are meant to be mutually reinforcing support functions. The core functions can be applied simultaneously within one activity itself or be applied in parallel to support two or more discrete activities within a country or regional activity. The functions are briefly described in the following.

\section{Continuous demand assessment}

This core function helps inform which of the remaining four core functions are most relevant for either a country or regional activity, and includes performing countryspecific studies and assessments. It aims to continuously assess country demands and needs to progress towards country-defined objectives by engaging with a broad range of local and critical stakeholders. Specifically, this core function helps to inform ACS's support strategy in each country and to regularly evaluate the relevance of project support during implementation.

\section{Health financing technical support}

The objective of this core function is to equip decisionmakers with competencies, skills and resources to 


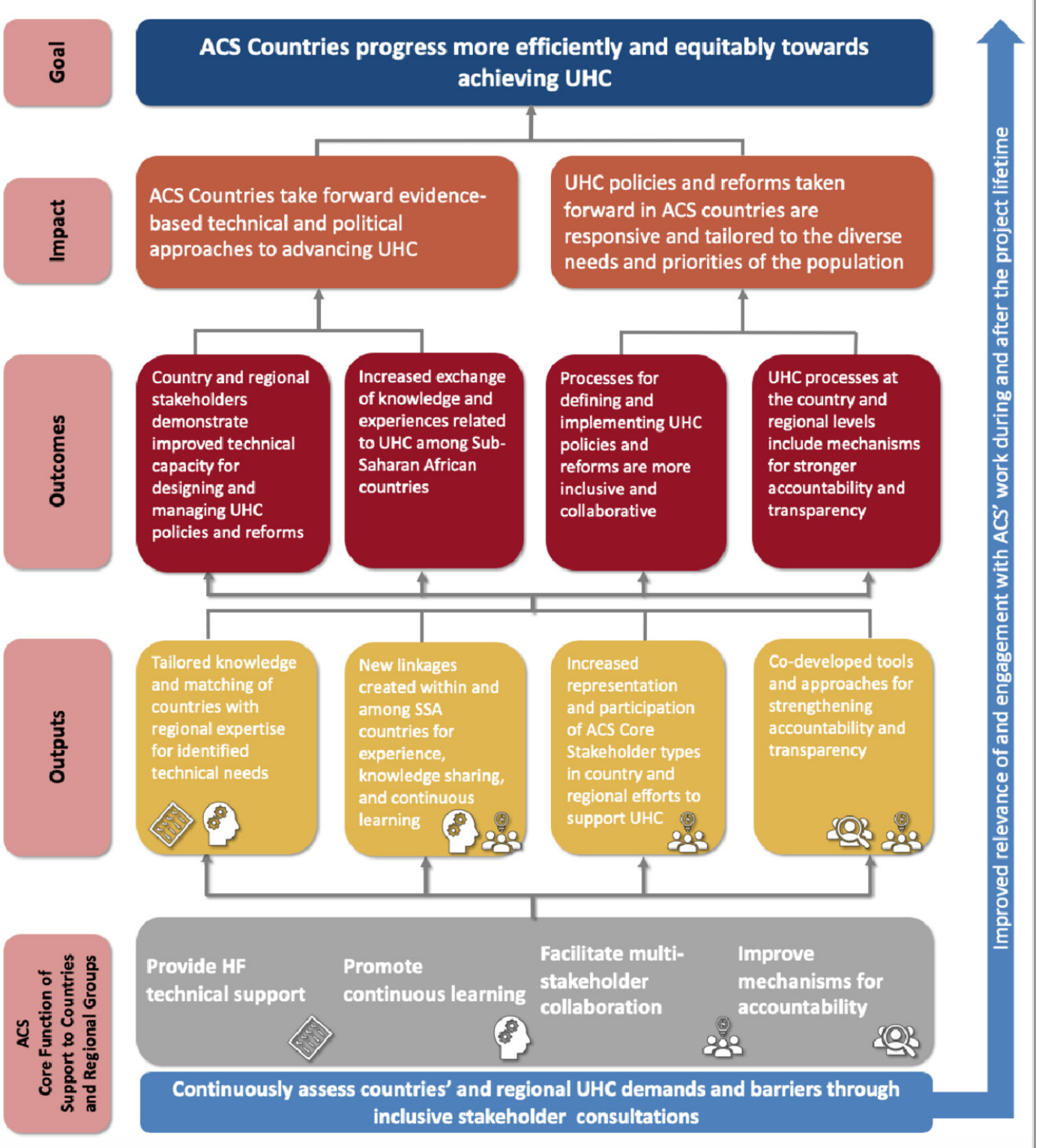

Figure 2 ACS's logic model. ACS, African Collaborative for Health Financing Solutions; HF, health financing; SSA, subSaharan Africa; UHC, universal heath coverage.

make informed health financing decisions for accelerated progress towards UHC. Specifically, ACS provides health financing technical support to countries through coaching and mentoring, capacity building, generating evidence, and developing tools and guidelines.

\section{Continuous learning}

This function supports the idea that, as a part of the design, both project and country-level activities are iterated upon, change and evolve based on the exchange of explicit and tacit knowledge. Ideally, this core function is a five-step process: (1) collect data, (2) analyse data, (3) share/communicate, (4) act and (5) iterate. Relevant primary and secondary data are collected and analysed, and knowledge products tailored to stakeholder needs are developed. Key learnings are then identified to continuously revise and improve the country's strategy and, where applicable, are generalised for use in other countries.

\section{Multi-stakeholder collaboration}

This core function consists of bringing all critical stakeholders to the decision-making table for a coherent march towards UHC where all concerned parties have their issues and priorities taken into consideration. This multi-stakeholder collaboration is enhanced through a three-step process: preparatory phase, trust building phase and success amplification phase. The preparatory phase consists of creating an environment conducive to collaboration and includes negotiating with the powerholder(s) for the inclusion of all key stakeholders in the UHC process, especially actors that may otherwise be excluded from a policy dialogue. Trust building is essential in the process of collaboration to ensure that 
countries' objectives are reached. Finally, focusing on and amplifying early successes produced by increased collaboration are a good way to showcase the value proposition of collaborative work, thereby strengthening the engagement and commitment of all parties involved.

\section{Accountability mechanisms}

This core function aims to ensure that all in-country actors have the necessary tools and resources required to hold decision-makers accountable for their actions. Tools such as strategic communication, regular reporting, advocacy and course correction allow constituents to check that commitments are effectively kept. Notably, this core function is the hardest to achieve-the concept of accountability is quite broad and elusive: accountability types are as diverse as financial, performance, political/ democratic and social accountability, among others. ${ }^{23} 24$

\section{ACS LOGIC MODEL IN PRACTICE: STRENGTHENING COLLABORATION, INCLUSIVITY, LEARNING AND ACCOUNTABILITY}

In the following section, we provide examples of how these functions materialised in practice in three countries-Benin, Namibia and Uganda-where the ACS project is providing support.

\section{The multi-stakeholder dialogue around health insurance in Benin}

The government of Benin requested ACS to support the implementation of its National Health Insurance scheme, called Assurance Maladie pour le Renforcement du Capital Humain (AM-ARCH), which is at a pilot stage. This AM-ARCH is managed by the ARCH Project Management Unit (UGP-ARCH) that reports directly to the President's Office. ACS conducted a continuous demand assessment to understand the needs and agree on the sequence for implementing activities. Priority actions identified included building strategies to make the AM-ARCH pilot implementation process more inclusive and developing and implementing a learning agenda for the pilot phase to capture critical events to prepare for scale-up.

Building trust and creating windows of opportunity to advocate for implementation processes to become more inclusive are key to foster multi-stakeholder participation. To support a more inclusive approach in the AM-ARCH implementation process, ACS initially proposed to the UGP-ARCH a list of potential stakeholders to be included in the demand assessment. This list was compiled from meetings and discussions that ACS had with key players of the UHC process in Benin as part of its consultation and preparatory missions. However, the adoption of the final list was at the discretion of the UGP-ARCH to decide which stakeholders they wanted to work with (or not).

Hesitations to associate certain groups such as trade unions, civil society and community members were observed. An opportunity to overcome this situation appeared with the learning agenda that the UGP-ARCH asked to set up. To this end, a Learning Agenda Workshop was held and was meant to bring together key stakeholders to understand and discuss the operational, behavioural and financial challenges with the AM-ARCH pilot scheme before scale-up. All attending parties agreed, as a group, on what success should look like for the pilot phase. The group identified four priority areas where the pilot must focus on learning and evaluate before scaling up: (1) developing a beneficiary complaint system; (2) improving quality of services related to care, patient admissions and availability of drugs and equipment; (3) refining reimbursement mechanism of health facilities; and (4) improving communication between the parties, including the population.

The Learning Agenda Workshop helped build trust in the effectiveness of collaboration. Following the meeting and after witnessing its success, the UGP-ARCH team members supported a more inclusive approach that resulted in previously 'excluded' stakeholders to be included in a stakeholders' forum on quality of services and invited to directly interact with decision-makers and implementers. This forum continues to be the venue where a multi-stakeholder group meets quarterly to discuss lessons learnt, challenges and emerging priorities related to the AM-ARCH pilot and the plans for its scale-up.

\section{Efficiency of health expenditure data collection in Namibia}

The continuous demand assessment in Namibia identified the need for regular detailed data on both health and HIV spending, in a context of reduced donor support for the development of the System of Health Accounts (SHA) and the National AIDS Spending Assessment (NASA). Stakeholders considered that the continued practice of implementing two separate yet somewhat duplicative exercises was not a sustainable approach for institutionalising these exercises domestically. To help address this issue, ACS prompted setting up an inclusive health financing technical working group (TWG) composed of 17 people including members from the government, donors and civil society. The members of this TWG were trained on a harmonised resource tracking approach. The differences between the tracking methodologies of SHA and NASA were presented and the benefits of combining both explained. The TWG adapted the harmonised approach to adequately incorporate both SHA and NASA requirements in a continuous learning process. This adoption enabled the TWG to generate consistent and reliable estimates of HIV and health expenditures while achieving efficiencies and reducing the workload by preventing the need to perform the two separate exercises and duplicative data collection efforts.

ACS also supported the development of (i) an advocacy brief on combining SHA and NASA resource tracking methodologies, (ii) a resource tracking guidance manual and (iii) a resource tracking methodological report, to facilitate shared learning and collaboration. These documents can also serve as reference documents for other countries wishing to conduct similar exercises. Actually, this combined resource tracking methodology initially developed and applied in Namibia has been adopted in Botswana, another ACS country. The learnings from Namibia, and subsequently 
Botswana, drew interest from Kenya (a non-ACS supported country) that wanted to use this method. This cross-country sharing of knowledge and learning processes can ultimately support an African-led momentum to streamline more efficient allocation and use of resources for HIV/AIDS service delivery within sub-Saharan countries.

\section{The UHC roadmap in Uganda}

In 2018, Uganda was at a critical point in moving its health financing strategy forward. While there were several ongoing health financing initiatives and a draft national health insurance bill before Parliament, there was lack of clarity among stakeholders on a unified definition of UHC and a concrete inclusive process to collaboratively advance UHC in Uganda. ACS supported the formation of an interministerial committee (IMC) tasked with the development of the national UHC roadmap. Following the inauguration of the IMC, the World Bank (WB) and the WHO offered to collaborate with the $\mathrm{MoH}$ and the USAID Mission to support the roadmap development process. The WB and the WHO recruited two consultants having experience in UHC roadmap development processes and a detailed understanding of the country's health and financing systems. The IMC then proposed formation of a smaller committee, the Core Committee, which worked closely with the consultants and served as a think tank, providing quality assurance and coordination of the UHC roadmap development process. This Core Committee reported to the IMC and spearheaded a series of activities including a desk review and a situational analysis and oversaw the development of a phased UHC roadmap. ACS partnered with the Uganda Healthcare Federation, a trusted partner to the $\mathrm{MoH}$ - this partnership enabled the ACS country lead to facilitate discussions, mobilise evidence and tap into regional expertise to inject technical advice as needed.

The IMC provided a platform for dialogue to define UHC for Uganda-an inclusive dialogue that brought together the expertise of diverse stakeholders across different sectors and served as a means to strengthen accountability. The IMC developed policy actions and integrated beneficiaries' needs through the voice of communities' representatives such as the Uganda National Health Consumers' Organisation. The roadmap was made publicly accessible and served as a reference document to encourage multisectoral participation, including the private sector, in the national COVID-19 response. To promote continuous learning, the collaboration that occurred in Uganda's UHC roadmap development was captured through a process documentation approach and shared with other country partners to inform the formation policy dialogue platforms (eg, AM-ARCH in Benin).

\section{CONCLUSION}

Supporting processes that advance UHC is at the heart of ACS activities and the logic model highlighting the five core functions described in this article. From the start, ACS's model of operation sought to depart from the common models of country assistance programmes, which are often characterised by donor-led and donor-driven initiatives, with minimal country ownership. Through technical assistance that places countries at the centre of the expression of needs, ACS strives to build ownership and responsibility for UHC processes among local communities and governments to move them forward. This approach builds on local expertise to address challenges that countries are facing and offers a blueprint for a broader shift in global health beyond this project. Developing an adaptable approach requires a balance between standard processes and contextualisation to specific country needs in order to create local ownership, facilitate the exchange of timely and relevant knowledge, foster locally led solutions and, ultimately, increase the likelihood of success and sustainability. But as with any innovative approach, learning was a key resource on which the project relied throughout its implementation. ACS has paved the way to change how donor aid for health is provided to countries in sub-Saharan Africa. Gains from ACS will continue beyond the project, and the logic model that guided its implementation has the potential to inform future in-country programmes that embed the pillars of accountability, collaboration and learning to achieve UHC by 2030.

\section{Author affiliations}

${ }^{1}$ Public Health, University of Ouagadougou Health Sciences Training and Research Unit, Ouagadougou, Kadiogo, Burkina Faso

${ }^{2}$ Duke-Margolis Center for Health Policy, Duke University, Washington DC, North Carolina, USA

${ }^{3}$ Results for Development Institute, Washington DC, North Carolina, USA

${ }^{4}$ Global Health Innovation Center, Duke University, Durham, North Carolina, USA

${ }^{5}$ Synergos, Windhoek, Namibia

${ }^{6}$ Uganda Healthcare Federation, Kampala, Uganda

${ }^{7}$ Global Health Policy Unit, University of Edinburgh, Edinburgh, UK

Twitter Joël Arthur Kiendrébéogo @jarthurk

Acknowledgements The authors thank the ACS country teams who provided details on the implementation of the project in their respective countries. This information was useful to refine the paper.

Contributors JAK designed the paper and wrote the first draft of the manuscript. Significant inputs were provided by the other coauthors. JAK revised the paper and the other coauthors contributed with comments. This paper is sharing the collective experience resulting from the ACS project of which all authors were actively part of.

Funding The ACS project is funded by USAID, Cooperative Agreement No. AIDOAA-A-17-00009.

Competing interests We have read and understood BMJ policy on declaration of interests and declare the following interests: all the authors were involved in the implementation of the ACS project whose implementation experience is shared in this paper.

\section{Patient consent for publication Not required}

Provenance and peer review Not commissioned; externally peer reviewed. Data availability statement There are no data in this work.

Open access This is an open access article distributed in accordance with the Creative Commons Attribution Non Commercial (CC BY-NC 4.0) license, which permits others to distribute, remix, adapt, build upon this work noncommercially, and license their derivative works on different terms, provided the original work is properly cited, appropriate credit is given, any changes made indicated, and the use is non-commercial. See: http://creativecommons.org/ licenses/by-nc/4.0/.

\section{ORCID iD}

Joël Arthur Kiendrébéogo http://orcid.org/0000-0002-7000-3712 


\section{REFERENCES}

1 George M. Being fair in universal health coverage: prioritize public health services for low- and middle-income countries. Am J Public Health 2016;106:830-1.

2 van Hees SGM, O'Fallon T, Hofker M, et al. Leaving no one behind? social inclusion of health insurance in low- and middle-income countries: a systematic review. Int J Equity Health 2019;18:134.

3 McKee M, Balabanova D, Basu S, et al. Universal health coverage: a quest for all countries but under threat in some. Value Health 2013;16:S39-45.

4 Bloom DE, Khoury A, Subbaraman R. The promise and peril of universal health care. Science 2018;361:eaat9644.

5 Borgonovi E, Compagni A. Sustaining universal health coverage: the interaction of social, political, and economic sustainability. Value Health 2013;16:S34-8.

6 Witter S, Anderson I, Annear P, et al. What, why and how do health systems learn from one another? insights from eight lowand middle-income country case studies. Health Res Policy Syst 2019;17:9.

7 Meessen B, Akhnif ELH, Kiendrébéogo JA, et al. Learning for universal health coverage. BMJ Glob Health 2019;4:e002059.

8 Kiendrébéogo JA, Meessen B. Ownership of health financing policies in low-income countries: a journey with more than one pathway. BMJ Glob Health 2019;4:e001762.

9 Rasanathan K, Bennett S, Atkins V, et al. Governing multisectoral action for health in low- and middle-income countries. PLoS Med 2017;14:e1002285.

10 Allotey P, Tan DT, Kirby T, et al. Community engagement in support of moving toward universal health coverage. Health Syst Reform 2019;5:66-77.

11 Olu O, Drameh-Avognon P, Asamoah-Odei E, et al. Community participation and private sector engagement are fundamental to achieving universal health coverage and health security in Africa: reflections from the second Africa health forum. BMC Proc 2019;13:7.
12 Wadge $\mathrm{H}$, Roy $\mathrm{R}$, Sripathy $\mathrm{A}$, et al. How to harness the private sector for universal health coverage. Lancet 2017;390:e19-20.

13 Clarke D, Doerr S, Hunter M, et al. The private sector and universal health coverage. Bull World Health Organ 2019;97:434-5.

14 Yamin AE, Mason E, IAP. Why accountability matters for universal health coverage and meeting the SDGs. Lancet 2019;393:1082-4.

15 OECD. Aid effectiveness 2011. progress in implementing the Paris agreement. OECD, 2012.

16 Bosmans M, Bossyns P, Flahaut A. Development cooperation as learning in progress: dealing with the urge for the fast and easy. ITGPress, 2016.

17 Kelley A, Cashin C. 3 shifts are needed in the global health community's support for health financing to advance UHC. Results Dev. Available: https://www.r4d.org/blog/three-shifts-role-globalhealth-financing-support-advance-uhc-r4ds-two-new-initiativessub-saharan-africa-2/ [Accessed Dec 15, 2019].

18 Kania J, Kramer M. Collective impact. Stanford Soc Innov Rev $2011 ; 7$.

19 World Health Organization. Everybody business : strengthening health systems to improve health outcomes : WHO's framework for action. Geneva: World Health Organization, 2007.

20 Chee G, Pielemeier N, Lion A, et al. Why differentiating between health system support and health system strengthening is needed. Int J Health Plann Manage 2013;28:85-94.

21 Kutzin J. A descriptive framework for country-level analysis of health care financing arrangements. Health Policy 2001:56:171-204.

22 Thoumi A, Davis N, Axelrod K, et al. African Collaborative of Health Financing Solutions - Consultation Phase Findings: Cross-Cutting Review of Emerging Themes, Challenges and Solutions, 2018. Available: https://acs.r4d.org/wp-content/uploads/2020/04/ Resources_ACS-Consultation-Phase-1.pdf [Accessed Dec 17, 2020].

23 Brinkerhoff DW. Accountability and health systems: toward conceptual clarity and policy relevance. Health Policy Plan 2004;19:371-9.

24 Bovens M. Analysing and assessing accountability: a conceptual framework. Eur Law J 2007;13:447-68. 